\title{
NEPHRITIS IN CHILDHOOD
}

\section{A CLINICAL ASSESSMENT OF THE ELLIS CLASSIFICATION \\ BY}

\author{
NORMAN S. CLARK \\ From the Department of Child Health, University of Aberdeen
}

(RECEIVED FOR PUBLICATION OCTOBER 28, 1955)

\begin{abstract}
Although it is now well over 100 years since Richard Bright described that group of diseases to which his name is still attached, no final agreement has yet been reached on their proper definition and classification. It is true that chronic pyelonephritis and essential hypertension have been defined as conditions clearly distinct from true nephritis in respect of their aetiology and early course, but nephritis itself, despite a multitude of classifications of varying degrees of complexity, still awaits a final analysis. Various and often multiple adjectives have been added to the word 'nephritis' in succeeding attempts to subdivide the condition into separate groups or entities, but it is notable that, of the many classifications proposed, not one has proved universally acceptable to both clinicians and pathologists.
\end{abstract}

The classification probably most widely used in this country at present is that of Ellis (1942) in which Bright's disease is subdivided into nephritis, essential hypertension and 'miscellaneous conditions' in which 'the renal disorder is incidental to some other disease'. Ellis regards nephritis itself as divisible into two clearly defined types differing in aetiology, clinical features, histology and prognosis. He defines type 1 nephritis as an illness of acute onset, usually at a short interval after an acute infection, with haematuria as the most prominent and constant symptom, and in many cases some degree of hypertension and oedema. The majority of cases ultimately recover completely. Type 2 nephritis he describes as a disease of insidious onset characterized by generalized oedema, gross albuminuria, a progressive course and a uniformly bad prognosis. His terms 'type 1' and 'type 2 nephritis', carrying with them the implication of two separate and distinct diseases, are now in very wide use in the British medical literature but, so far as I know, the only critical appraisals of Ellis's views have been those of Davson and Platt (1949) and Enticknap and
Joiner (1953). Both papers report a few cases which do not fit easily into type 1 or type 2 of Ellis's classification. Davson and Platt, while reserving judgment on whether type 1 and type 2 are separate entities aetiologically, consider that 'as a practical classification of nephritis the Ellis classification is an advance', while Enticknap and Joiner conclude that 'this classification has little to recommend it from a descriptive point of view'.

Some years ago, in the course of a clinical trial of an antihistamine drug in the treatment of nephritis, I had occasion to extract and study the records of 265 consecutive cases of nephritis admitted to the Royal Aberdeen Hospital for Sick Children. The considerable difficulty experienced in fitting all the cases into two separate and clearly defined types prompted further consideration of these cases in the light of the Ellis classification. This analysis has been, of necessity, purely clinical, for comparatively few patients died and the amount of necropsy material available was quite insufficient to form the basis of any criticism of the Ellis classification from this angle. The clinical details, including the results of a long-term follow-up, are sufficient, however, for a clinical study of the natural history of nephritis originating in childhood, and the results of this study are here presented with particular reference to the validity of the Ellis classification from the clinical standpoint.

\section{Material}

This survey covers all cases admitted to the Royal Aberdeen Hospital for Sick Children between April, 1934, and May, 1952, in which a final diagnosis was made of 'nephritis' of any variety (excluding, of course, pyelonephritis). I have personally seen all cases admitted subsequently to January, 1946. The information on cases admitted before this date is derived entirely from the case notes. 
During this period a final diagnosis of nephritis has been made in 265 cases. In addition, eight children when first seen were all in varying stages of renal failure with azotaemia, polyuria and urine of fixed, low specific gravity. This syndrome in childhood is probably less frequently due to true chronic nephritis than to congenital abnormalities of the kidney or to chronic urinary infection (Clark, 1951). Congenital abnormalities of the kidneys were found at necropsy in several of these eight cases, and in none of them was there any history of a previous attack of nephritis. As there is no clear evidence that any one of them represents the terminal stage of true nephritis, I do not propose to consider them here.

During the period of this survey the diagnosis 'nephrosis' does not appear in the disease index; no case, therefore, has been excluded as being an example of this condition.

Of these 265 patients, 20 died in the initial illness and three are known to have died subsequently. Attempts to assess the final outcome of the disease by follow-up examination were successful in 156 patients, and information was received from various sources on the present state of a further 19 who could not attend for examination. The interval from the onset of symptoms to the final follow-up examination varied from one to 13 years (in only 13 cases was it less than two years). Sixtyseven cases remain untraced.

\section{Classification}

Of the 265 cases, 239 conform closely to Ellis's description of type 1 nephritis; they had an illness of acute onset, usually at an interval of one or two weeks after an acute infection, with haematuria as the most constant symptom and some degree of hypertension and oedema in many cases. One proviso must be made to this statement, however, namely that Ellis and certain other workers might classify some of these cases as 'acute focal nephritis'. Ellis specifically excludes from his cases of type 1 nephritis 35 cases of acute focal nephritis and puts them under the heading of miscellaneous conditions in which the renal symptoms are incidental to some other disease.

The term 'acute focal nephritis', first proposed by Volhard and Fahr, has been widely used to cover a type of case in which haematuria appears at the height of an acute infection and is not accompanied by either oedema or hypertension. This condition is described in some detail by Fishberg (1954) who maintains that hypertension and oedema are consistently absent throughout the course of the disease and that the prognosis is invariably excellent. He considers that these cases resemble acute nephritis superficially only. While Ellis apparently also feels that this is a separate entity and excludes such cases from his group of type 1 nephritis, he states that in two of his 35 cases 'albuminuria persisted between the attacks and after many years the blood pressure rose and death occurred in renal failure'. As $10 \%$ of his cases of type 1 nephritis followed a similar course, it seems that the long-term prognosis in both groups is substantially the same, a finding at variance with Fishberg's opinion that the prognosis in acute focal nephritis is always excellent. As Ellis does not claim that hypertension and oedema are always found in cases of type 1 nephritis, the grounds for differentiation between this type and acute focal nephritis appear to be slender.

Careful consideration of the case records of the present series leads me to agree unhesitatingly with Payne and Illingworth (1940) that there are no clinical grounds whatever for distinguishing acute focal nephritis as an entity. Those case histories which show an interval of less than one week between the onset of an acute infection and the appearance of the first signs of nephritis have been scrutinized with particular care; they show all gradations of severity in the initial illness and hypertension has been marked in many of them. Conversely, scrutiny of the records of those who have shown neither hypertension nor oedema at any stage of their illness shows no relationship between these features and onset at the height of an acute infection, and indeed many of these cases showed no evidence at all of active infection on admission.

In five $(2 \%)$ of the 239 cases haematuria was consistently absent on daily microscopic examination of the urine during the first week in hospital. In their initial picture and subsequent course these cases appear to fit into type 1 in every other respect, and it seems, therefore, that even haematuria is not an absolutely constant finding in the early stages.

No other significant difference from Ellis's description of the symptoms and course of type 1 nephritis was noted in any of these cases.

In two cases the information available from the notes is too scanty to permit of definite classification.

There remain, therefore, 24 cases which cannot at once be accepted as examples of type 1 nephritis. The histories of these cases (summarized in the Appendix) must now be considered. To simplify discussion they are presented in four groups, all the members of each group having certain features in common. 
Group 1. These four cases have all presented a rather similar picture. All had gross oedema with effusion in one or more of the serous cavities, persisting, except in Case 183, over several months. A15 and A23 had a marked rise in blood cholesterol and 183 showed a reversal of the albumin/globulin ratio. All showed a persistent very heavy albuminuria. While these features are more commonly associated with type 2 nephritis, the other findings would seem to place these four cases as severe examples of type 1 . Nevertheless, Case 68 died 10 years after her original illness and Cases 183, A15 and A23 are alive and in fair health, though with evidence of persisting renal damage after two or three years, as against the few months which Ellis quotes as the usual course of type 1 nephritis, showing gross and persistent oedema.

Group 2. These six cases again show certain general resemblances to one another. Cases 123, 151, A14 and A37 had no history of recent infection and Case 9 a doubtfully significant history. Repeated microscopic examination showed no red blood cells in the urine of Case A8, and red blood cells were scanty and only occasionally found in Cases 123, 151, A14 and A37. In the remaining case the only microscopic examination noted showed me red blood cells. All cases showed a raised blood cholesterol level except Case A8 in which this investigation was not carried out. Cases 123, A14 and A37 had gross oedema and Cases 151 and A8 moderate oedema. These features and the unexplained purulent abdominal effusion in Case 151 are all more in keeping with Ellis's type 2 nephritis than with type 1 . While the type 2 features are more prominent in this group than in the previous one, all cases still bear many resemblances to type 1 and probably some workers who use the Ellis classification would accept them in this category.

Group 3. These six cases should probably be placed in type 2 of Ellis's classification but they all show certain unusual features. Cases 41, 201 and A32 had a history of acute respiratory infection one or two weeks before nephritic signs appeared. The initial illness of Case 41 conformed closely, apart from its relatively brief course, to Ellis's description of type 2 nephritis, but on her second admission there is a very clear history of macroscopic haematuria at home, although in hospital blood was only seen microscopically. Case 117 had macroscopic haematuria in hospital on two occasions and his blood pressure remained elevated for over three months. Both these patients were alive and clinically well with normal urine 10 and seven years respectively after the onset of their illnesses.
Case 201 had a fairly clear-cut history of an attack of type 1 nephritis three months before admission, but his course in hospital was that of type 2. Case A31 is difficult to classify with certainty because she was admitted to hospital late in her illness when the oedema had already disappeared. On the whole the findings were more in keeping with type 2 nephritis, but again there was a history of 'red' urine at the onset.

Case A32 for four months after admission ran a type 2 course and then developed persistent haematuria which was occasionally macroscopic; although his plasma proteins twice fell to $3 \cdot 5 \mathrm{~g}$. \%, they were frequently normal and his albumin/ globulin ratio was never reversed. Case A36 on hi first admission also presented a type 2 picture, but on re-admission had macroscopic haematuria.

Thus all six cases showed gross haematuria at some stage of their course which, according to Ellis, is rare in type 2 nephritis. Case A36, the only one to come to necropsy, showed certain features of both types of nephritis.

Group 4. The eight cases in this last group conform fairly closely in the nature of their initial illness to Ellis's type 2 nephritis, but their course has not shown the steady downward progress which he describes as characteristic of the disease. Four of these children showed no evidence of persistent renal damage when examined from one to five years after the onset of their illnesses, and another is known to be alive and apparently well after three years, although it was not possible to examine her or to obtain a specimen of urine. Two died in their initial illness and only one (Case 145) has shown evidence of continuing renal disease. While the number of cases is too small to justify any firm conclusions regarding prognosis, the results are obviously less uniformly gloomy than in Ellis's large series of 145 cases in which only five recovered. Ellis also lays some stress on the infrequency of a history of antecedent infection in cases of type 2 nephritis (less than $5 \%$ ); it should be noted that five of the above eight cases have a fairly clear history of upper respiratory infection shortly before the onset of nephritic symptoms.

If we try to fit the cases in this series into the Ellis classification it appears, therefore, that of the 24 cases which cannot be accepted as definite examples of type 1 nephritis, only eight appear to fall clearly into type 2 . The remaining 16 cases can only be accepted in either type with certain reservations, and in all of them the clinical picture lies somewhere between the picture of type 1 nephritis and that of type 2 nephritis. 


\section{Discussion}

Ellis's contention that nephritis can be divided on clinical grounds into two clear-cut types is not upheld by the findings in this series. The general impression left after the consideration of these cases is that nephritis presents a complex and infinitely variable clinical picture with, at one end of the scale, a large group of cases in which the dominant features are acute onset and haematuria and, at the other end of the scale, a small group of cases in which the dominant features are sub-acute onset, oedema and albuminuria, while between these two extremes lie a number of cases which cannot be formed into a homogenous group or groups but

ich show varying combinations of the symptoms presented by the cases at both ends of the scale.

After consideration of the clinical features of the present series of cases, I find myself in general agreement with the view of Enticknap and Joiner quoted above that 'this classification has little to recommend it from a descriptive point of view'. While it may be useful from the point of view of prognosis and management to subdivide cases of rephritis into two groups, I feel that this should be regarded as a matter of clinical convenience and not as implying any hard and fast distinction between two different diseases. There is, I think, much to be said for reverting to the older titles of 'acute haemorrhagic nephritis' and 'sub-acute oedematous nephritis' which are generally descriptive of the usual clinical pictures and do not carry the implication of a fundamental distinction between two different diseases.

In my view the varied clinical pictures in the present series can only be explained on the assumption that they are different expressions of one indivisible disease process. This is, to a large extent, the view of Snoke (1937) and Payne and Illingworth (1940), but with one difference which is, I think, of some importance. They, in common with most workers, who do not regard the oedematous type as a separate disease, consider it to be a stage in the development of nephritis, a sequel to a previous attack of acute haemorrhagic nephritis. They suggest that the absence of a history of a previous frank attack of acute nephritis in many of their oedematous cases can be explained on the assumption that there has in fact been a previous attack so mild as to remain undetected. That acute nephritis may, on occasion, be so mild as to escape detection without careful examination of the urine is undoubtedly true, but there seems no good reason to suppose that such mild attacks are more likely to be followed by the subacute oedematous picture than are more obvious and severe attacks. Yet this assumption of a previous unrecognized acute attack must be invoked in the great majority of cases of oedematous nephritis if this condition is to be considered as a later stage in the evolution of nephritis, for the incidence of recognized previous attacks of acute nephritis has been even lower in most reported series than the $33 \%$ quoted by Payne and Illingworth. This assumption is, by its very nature, insusceptible of proof, nor is there any convincing indirect evidence to support it, and it is not surprising that its validity has been questioned. Indeed, the absence of a history of an antecedent frank attack of haemorrhagic nephritis in the great majority of cases of oedematous nephritis has been used as an argument by those who consider that the two conditions are different diseases.

If, however, instead of regarding acute haemorrhagic nephritis and subacute oedematous nephritis as different stages of the same disease, we regard them as different expressions of it, no such assumption is necessary and this conception is certainly more in keeping with the occasional case such as Case 41 (and possibly also Cases A32 and A36) in which the initial picture was that of oedematous nephritis while, at a later stage, the symptoms were those of the haemorrhagic type.

Of the factors which determine the mode of expression and the probable course of nephritis in the individual case we are still largely ignorant, and until our knowledge of the underlying pathological processes is considerably extended, it appears that attempts to subdivide the manifestations of nephritis are more likely to confuse than clarify our understanding of the problem.

\section{Summary}

The case histories of 265 cases of nephritis in childhood have been reviewed and an attempt made to subdivide them into two types in accordance with the Ellis classification.

While 239 cases conform fairly closely to Ellis's description of type 1 nephritis, only eight can with certainty be described as type 2 and of these at least four appear to have made a complete recovery.

The remaining cases appear to fall somewhere between the two types and it is suggested, therefore, that type 1 and type 2 nephritis are not, as Ellis suggests, different diseases, but merely the two extremes of a single clinical picture which is capable of very considerable variation. It is further suggested that, if nephritis is to be subdivided at all, this can only be done at the descriptive level and as a matter of convenience, and that there is much to be said for reverting to the older titles of 'acute 
haemorrhagic nephritis' and 'sub-acute oedematous nephritis' which do not carry the implication of a distinction between two different diseases. The pictures which these titles describe appear to be different expressions rather than different stages of the same disease process.

\section{A P P E N D I X*}

\section{Group 1}

Case 68. A girl aged 10 years was admitted on August 12, 1937, with a history of generalized oedema of gradual onset about four months previously. One month or less before the oedema was first noted, she had a febrile illness diagnosed as 'influenza'. No haematuria was noticed at home. On admission she showed marked generalized oedema with effusion in the right chest; blood pressure $140 / 108 \mathrm{~mm}$. $\mathrm{Hg}$; blood urea $57 \mathrm{mg}$. \%; urine, albumin ++ , and on deposit, red blood cells. Hypertension and microscopic haematuria persisted thoughout eight months in hospital. Her blood pressure rose to a maximum of $190 / 130 \mathrm{~mm}$. $\mathrm{Hg}$ and haematuria was at times macroscopic. Oedema increased for the first three months, then gradually disappeared in the next two months, in which her weight fell from $91 \frac{1}{2} \mathrm{lb}$. to $70 \mathrm{lb}$. She died at home in uraemia 10 years later.

Case 183. A girl aged 10 years was admitted on June 10, 1946. Three weeks previously she had a mild attack of scarlet fever; one week later the legs and abdomen began to swell and she complained of persistent headache. On admission she had generalized oedema and ascites; blood pressure $150 / 100 \mathrm{~mm}$. $\mathrm{Hg}$; blood urea level $172 \mathrm{mg}$. \% ; urine, albumin +++ , and on deposit, red blood cells. The oedema disappeared after one month and the blood pressure fell to $100 / 70 \mathrm{~mm}$. $\mathrm{Hg}$ in six weeks, but the blood urea level only once fell below $40 \mathrm{mg} . \%$ in 11 months in hospital. Very heavy albuminuria and haematuria that was at times macroscopic persisted. The plasma proteins on two occasions showed albumin/globulin ratios of $0 \cdot 87 / 1$ (total protein, $4 \cdot 66 \mathrm{~g}$.) and $0 \cdot 80 / 1$ (total protein, $4.94 \mathrm{~g}$.). When last seen two and a half years after the onset of her illness she was in fair condition; the blood pressure was 110/60 and the blood urea level was $34 \mathrm{mg}$. \%, but she still had heavy albuminuria.

Case A15. A girl aged 11 years was admitted on February 28, 1949. She had no history of recent infection. Two weeks before admission she complained of headache, passed dark brown urine, and was thought to have a puffy face. On admission there was oedema of the face only; blood pressure $110 / 80 \mathrm{~mm}$. $\mathrm{Hg}$; blood urea, $30 \mathrm{mg}$. \% ; urine, albumin +++ and macroscopic blood. The oedema became generalized and ascites appeared. The blood pressure remained normal and the

- Cases are numbered consecutively in the order of their admission. The last 62 cases admitted are numbered A1 to A62; this division into two series is of no significance for the purpose of the present paper. blood urea level rarely rose above $40 \mathrm{mg}$. $\%$; the blood cholesterol level rose to $446 \mathrm{mg}$. \%. Albuminuria continued gross; Esbach readings on 24-hour specimens on 18 occasions were almost invariably above 5 parts, and on one occasion rose to 22 parts. Haematuria persisted (and was at times macroscopic) throughout her eight months in hospital. When last seen over two years after the onset of her illness she was in fair general condition; her blood pressure was $118 / 75 \mathrm{~mm}$. $\mathrm{Hg}$; blood urea, $24 \mathrm{mg}$. \%; the urine contained albumin ++ and scanty red blood cells. She has had several flare-ups with gross haematuria in the interval.

Case A23. A boy aged 4 years was admitted on July 20, 1949. Three weeks previously he developed a sore throat followed after an interval of two weeks by the appearance of generalized oedema, by repeated vomiting, and by the passage of dark urine. On admission he showed generalized oedema with ascites and a left pleural effusion. His blood pressure was $126 / 84 \mathrm{~mm}$. $\mathrm{Hg}$ and his blood urea level $33 \mathrm{mg}$. \%. His urine contained albumin (6 parts Esbach) and macroscopic blood. The oedema increased and became very gross, his maximum weight, two months after admission, being $57 \mathrm{lb}$. His blood pressure at this time rose to $140 / 106 \mathrm{~mm}$. Hg. Following hot packs and abdominal paracentesis he lost $10 \mathrm{lb}$. in weight in 10 days, and four months after admission he weighed $35 \mathrm{lb}$. and there was no detectable oedema. His blood pressure remained slightly elevated. Throughout seven months in hospital albuminuria and microscopic haematuria persisted. The blood cholesterol level at one time reached $504 \mathrm{mg}$. \%. Two and a half years after admission he was well and attending school regularly. His blood pressure was $120 / 80 \mathrm{~mm}$. $\mathrm{Hg}$, the urine contained persistent traces of albumin and an Addis count on a 12-hour specimen showed 2,970,000 red blood cells.

\section{Group 2}

Case 9. A girl aged 3 years was admitted on August 29,1934 . Two months before admission she developed measles, after which she was left with enlarged tonsillar nodes. Four days before admission her face became puffy and her urine contained albumin. On admission she had doubtful oedema of the face only and her charts show no loss of weight during her six weeks in hospital. Her blood pressure was $108 / 80 \mathrm{~mm}$. $\mathrm{Hg}$, her blood urea level $45 \mathrm{mg}$. \% and blood cholesterol $350 \mathrm{mg}$. \%. The urine contained albumin ++ and microscopic examination showed many casts but no red blood cells. Unfortunately there is no record of any subsequent microscopic examination, but the albuminuria diminished and ceased entirely after three weeks. Her subsequent history is unknown.

Case 123. A girl aged 11 years was admitted on November 10, 1941. There was no history of recent infection. Three weeks before admission she developed swelling of the face, vomited repeatedly, complained of pain in the abdomen and back, and passed scanty dark urine. On admission she showed extensive oedema; 
her blood pressure was $130 / 94 \mathrm{~mm}$. $\mathrm{Hg}$ and blood urea level $42 \mathrm{mg} . \%$. The urine contained albumin ++ and macroscopic blood. Fairly heavy albuminuria continued throughout eight months in hospital but haematuria diminished rapidly and repeated microscopic examination subsequently showed no red blood cells. The blood cholesterol level varied between 432 and $700 \mathrm{mg} . \%$. Oedema fluctuated throughout her stay in hospital and was at times gross and generalized and at times absent. She died at home one year after the onset of her illness.

Case 151. A boy aged 8 years was admitted on July 14, 1944. He had no history of recent infection. One week before admission his legs began to swell and he vomited repeatedly and passed scanty urine containing albumin. On admission he showed oedema of the face and legs; his blood pressure was $124 / 90 \mathrm{~mm}$. $\mathrm{Hg}$, his blood urea level $87 \mathrm{mg}$. \%, and blood cholesterol $328 \mathrm{mg}$. \%. The urine contained albumint and red blood cells on microscopic examination. Ten days after admission the abdomen became swollen. Next day paracentesis produced 1 pint of greenish turbid fluid, sterile on culture but containing many polymorphs. (No chemotherapy had been given.) Two days later laparotomy produced a large volume of similar fluid again sterile on culture. No cause for the peritonitis was apparent. The oedema then gradually disappeared and the albuminuria diminished to a trace. On discharge on September 14, and when he was seen again two months later, the urine still showed traces of albumin but no red blood cells were seen. His subsequent history is unknown. (He was a boarded-out child and all attempts to trace him have failed.)

Case A8. A girl aged 6 years was admitted on October 22, 1948. One week previously, on the day of her discharge from hospital after treatment for acute otitis media, her face became swollen and her urine was found to contain albumin. On re-admission she was found to have oedema of the face, back and legs; her blood pressure was $185 / 145 \mathrm{~mm}$. $\mathrm{Hg}$ and the blood urea level $60 \mathrm{mg}$. \%. The urine contained albumin + but no red blood cells. Her blood pressure fell to $95 / 65 \mathrm{~mm}$. $\mathrm{Hg}$ and the oedema disappeared completely one week after admission. Her urine was by then free from albumin and no red blood cells were ever seen on daily microscopic examination from the time of her admission. She was seen at intervals up to five and a half years from the onset of her illness and has remained well and free from any signs of renal damage (blood pressure, 120/80; routine urine examination and Addis count, normal).

Case A14. A boy aged 10 years was admitted on February 18, 1949. He had no history of recent infection. Four days before admission his face became swollen and he complained of abdominal pain. On admission he was breathless on moderate exertion and showed marked generalized oedema and a right pleural effusion. There was definite cardiac enlargement but no murmurs were heard; the neck veins were distended
$1 \mathrm{in}$. above the manubrium and the liver edge was three fingerbreadths below the costal margin. His blood pressure was $140 / 100 \mathrm{~mm}$. $\mathrm{Hg}$, blood urea level $60 \mathrm{mg} . \%$, and blood cholesterol level $288 \mathrm{mg}$. \%. The urine contained albumin, 0.5 parts Esbach in a 24-hour specimen; no red blood cells were seen on microscopic examination. Signs of cardiac failure disappeared rapidly and after two weeks the oedema had gone and blood pressure had fallen to $120 / 85 \mathrm{~mm}$. $\mathrm{Hg}$. Traces of albumin persisted in the urine up to three weeks after admission, but daily microscopic examination showed very occasional red blood cells on three occasions only. When last seen six months later he was well, his blood pressure was $120 / 70 \mathrm{~mm} . \mathrm{Hg}$ and his urine normal.

Case A37. A boy aged 1 year 4 months was admitted on November 3, 1950. There was no history of recent infection. Two weeks before admission he developed generalized oedema and passed dark urine. On admission he was generally oedematous; his blood pressure was $100 / 80 \mathrm{~mm}$. $\mathrm{Hg}$ and blood urea level $70 \mathrm{mg}$. \%. The urine contained albumin ++ and scanty red blood cells. The oedema increased and he developed ascites, his maximum weight two weeks after admission being $34 \mathrm{lb}$. At this time the blood cholesterol level was $440 \mathrm{mg} . \%$ and there was still gross albuminuria, but red blood cells were usually absent on microscopic examination. Then oedema diminished gradually and had disappeared two months after admission when his weight was $22 \mathrm{lb}$. Albuminuria had also ceased. Two weeks later, accompanying an upper respiratory infection, albuminuria recurred but with virtual absence of even microscopic haematuria. Traces of albumin were still present when he was discharged three and a half months after admission. When last seen one and a half years after admission he was well, and urine examination showed no abnormality.

\section{Group 3}

Case 41. A girl aged 8 years was admitted on April 3, 1936. One month previously she developed a sore throat, followed one week later by a swelling of the eyelids. The oedema gradually spread, and on one occasion her urine was thought to have been dark. On admission she had marked oedema of the face and doubtful oedema elsewhere. Her blood pressure was $116 / 70 \mathrm{~mm}$. $\mathrm{Hg}$, blood urea level $30 \mathrm{mg}$. \%, and blood cholesterol level $512 \mathrm{mg}$. \%. The urine contained albumin ++ , and microscopic examination showed casts, pus cells and renal epithelium, but no red blood cells. During the first three weeks in hospital the oedema became gross and generalized and was accompanied by ascites and left pleural effusion. During the next three weeks the oedema gradually disappeared and albuminuria diminished. On 11 occasions microscopic examination showed no red blood cells in the urine. Two months after admission albuminuria had ceased, and when she was discharged one month later she had apparently made a complete recovery. She remained fairly well for one year but her parents noted that her 
ankles were frequently swollen in the evening. She was then re-admitted with a 10 days' history of swelling of the face and legs, headache and the passage of scanty red urine. On admission her blood pressure was 110/78 $\mathrm{mm} . \mathrm{Hg}$, and her urine contained albumin ++ and many red blood cells. For two and a half months oedema of varying degree persisted, her weight showing fluctuations between 73 and $85 \mathrm{lb}$. When the oedema was maximal her blood pressure rose and for over three weeks the diastolic pressure was between 92 and $104 \mathrm{~mm}$. Hg. Microscopic haematuria persisted for 10 days after admission, then ceased and remained absent, though casts were consistently present. Albuminuria persisted and when she was discharged three months after admission, a 24-hour specimen contained 1 part Esbach. Over 10 years later she was very well, the urine was normal and the blood urea level was $37 \mathrm{mg}$. \%. She was said to have recovered completely six months after her discharge from hospital and to have remained well ever since.

Case 117. A boy aged 7 years was admitted on April 10, 1941. Six days before admission he developed coryza and 24 hours later his face and legs began to swell. On admission he showed oedema of the face, legs and back. His blood pressure was $118 / 90 \mathrm{~mm}$. $\mathrm{Hg}$, and his blood urea level $30 \mathrm{mg}$. \%. The urine contained albumin, 12 parts Esbach, and scanty red blood cells. On two occasions shortly after admission macroscopic haematuria was present and on three subsequent examinations red blood cells were seen microscopically; a considerable number of microscopic examinations thereafter showed casts only. Albuminuria fluctuated but was gross at the time of his discharge after 10 months in hospital. Oedema also varied considerably but was usually gross and generalized, with ascites; six weeks after admission, immediately following a plasma transfusion, he had a marked diuresis and his abdominal girth decreased by 8 in. in one week; two weeks later the oedema recurred and again became gross but had disappeared completely before his discharge. His blood pressure rose and remained elevated for three months after admission, the diastolic pressure usually being between 90 and $106 \mathrm{~mm}$. Hg. The blood cholesterol level in the first two months was 840 and $713 \mathrm{mg}$. \%, but had fallen to $160 \mathrm{mg}$. \% before his discharge. The highest blood urea level recorded was $54 \mathrm{mg}$. \%. Seven years later he was clinically well, his blood pressure was $130 / 70 \mathrm{~mm}$. $\mathrm{Hg}$ and his urine was free from albumin and abnormal deposit.

Case 201. A boy aged 5 years was admitted on March 4, 1948. In December, 1947, he had a sore throat followed after two weeks by swelling of the face and ankles and obvious haematuria. He was kept in bed at home for four weeks, apparently recovered, and had been up and about for four weeks when the feet and legs again swelled up and red blood cells were found in the urine. On admission he showed oedema of the face and sacral region. His blood pressure was 100/70 $\mathrm{mm} . \mathrm{Hg}$ and his blood urea level $19 \mathrm{mg} . \%$. His urine contained albumin ++ , but no red blood cells were seen on microscopic examination. The oedema fluctuated considerably and was at times gross and generalized, but had disappeared seven weeks after admission, when he was discharged to remain in bed at home. On July 26, 1948 , he was re-admitted with gross generalized oedema which persisted till his discharge one month later. Throughout both periods in hospital albuminuria remained gross but repeated microscopic examination showed red blood cells on two occasions only. The blood cholesterol level varied between 624 and $928 \mathrm{mg}$. $\%$ and plasma proteins between $4 \cdot 03$ and $7 \cdot 61 \mathrm{~g} . \%$, the lowest albumin/globulin ratio being $0 \cdot 78 / 1$. His blood pressure remained normal. He died at home in December, 1948.

Case A31. A girl aged 3 years was admitted on June 10, 1950. She had no history of infection after an attack of measles one year previously. Thereafter she never seemed really well, and three months before admission she developed generalized oedema. The urine is said to have been 'rather red' about this time. The oedema slowly disappeared before she was admitted on account of persistent albuminuria. On admission she appeared well and had no detectable oedema. Her blood pressure was $110 / 75 \mathrm{~mm}$. $\mathrm{Hg}$, blood urea level $16 \mathrm{mg}$. \%, blood cholesterol level $245 \mathrm{mg}$. \%, and plasma proteins $4.46 \mathrm{~g}$. \% with an albumin/globulin ratio of 1.41/1. The urine contained albumin, 4 parts Esbach, but no red blood cells. During four months in hospital the urine continued to show albumin ++ but no red blood cells were ever seen. She was seen on three occasions up to two years from the time of her admission during which period she remained very well. Noncatheter specimens of urine showed faint traces of albumin on two of these examinations, but no abnormal deposit was ever present and an Addis count on her last visit showed only 100,000 red blood cells and no casts in a 12-hour specimen.

Case A32. A boy aged 7 years was admitted on June 12, 1950. Six weeks previously he developed 'croup', and two weeks later swelling of the face and ankles appeared. On admission he showed oedema of the face and legs. His blood pressure was $122 / 78 \mathrm{~mm}$. $\mathrm{Hg}$, his blood urea $28 \mathrm{mg}$. \% and his plasma proteins 3.5 g. $\%$. The urine contained albumin, 6 parts Esbach, and microscopic examination showed many casts but no red blood cells. During 14 months in hospital oedema varied considerably but was usually gross and generalized; he developed ascites, which required tapping on several occasions, and bilateral pleural effusions. The oedema ultimately disappeared after two short courses of A.C.T.H., each followed by a brisk diuresis which brought his weight from $81 \frac{1}{2} \mathrm{lb}$. to $61 \mathrm{lb}$. His blood pressure was elevated for a prolonged period, the highest reading being $138 / 102 \mathrm{~mm}$. $\mathrm{Hg}$, but had fallen to normal before his discharge. The blood urea level remained within normal limits, the blood cholesterol level varied between 300 and $830 \mathrm{mg} . \%$, and the plasma proteins were never below $3.5 \mathrm{~g}$. \%, the 
lowest albumin/globulin ratio recorded being 1/11/1 The urine showed heavy albuminuria throughout, the Esbach readings varying between 4 and 20 parts. Repeated microscopic examination in his first four months in hospital showed no red blood cells in the urinary deposit, but microscopic haematuria then began and persisted with brief intermissions throughout his stay in hospital: on several occasions the haematuria became macroscopic. An Addis count six months after admission showed: red blood cells $1,940,000$, and casts $3,020,000$, in a 12 -hour specimen.

Slight oedema recurred for a time after his discharge from hospital, but when last seen three years after the onset of his illness he was outwardly well and active. He was free from oedema and his blood pressure was $110 / 75 \mathrm{~mm}$. $\mathrm{Hg}$, but the urine contained albumin ++ .

Case A36. A boy aged 3 years was admitted on October 31, 1950. His illness began insidiously three months before admission when he developed intermittent swellings of the face and limbs. The urine appeared dark and the output was low. On admission he showed oedema of the face, back and legs. His blood pressure was $120 / 90 \mathrm{~mm}$. $\mathrm{Hg}$, blood urea level $47 \mathrm{mg}$. $\%$, and plasma proteins $5 \cdot 25 \mathrm{~g}$. $\%$ with an albumin/globulin ratio of $0 \cdot 99 / 1$. The urine contained albumin ++ and microscopic examination showed no red blood cells. Throughout five weeks in hospital oedema varied and was at times generalized; his blood pressure fell to $112 / 78 \mathrm{~mm}$. $\mathrm{Hg}$; albumin was constantly in the urine, but red blood cells were found on only four out of 16 microscopic examinations. He remained in bed at home for one month after discharge and was then re-admitted with generalized oedema and gross haematuria. The oedema varied and the haematuria diminished slowly for six weeks. He then developed measles; 10 days later he showed less oedema but was otherwise unchanged. The urine contained albumin ++ and scanty red blood cells. A course of A.C.T.H., $10 \mathrm{mg}$. six-hourly, was begun, and on the second day of this course a very profuse diuresis began and persisted until he became dehydrated: despite intravenous fluids he collapsed and died (nine months after the onset of his illness).

Necropsy showed some generalized dehydration, slight pulmonary oedema and pale wet kidneys of normal size. No other abnormality was demonstrated. The histological report on the kidneys was as follows:

'Nearly all the glomeruli showed some degree of sclerosis, although few, if any, appeared to be completely effete. This sclerosis was often associated with digitation of the glomerular tufts and numerous examples of adhesion between the tuft and the capsule were noted. Nevertheless, as a rule, the glomeruli were not unduly cellular; the glomerular capillaries were freely patent; epithelial crescent formation was only occasionally seen and there was no notable fibrous thickening of the capsules of Bowman. The tubular elements were comparatively healthy in appearance, apart from a minor degree of dilatation as an occasional feature; a moderate number of hyaline casts were present: deposits of pigment were often present in the loops of Henle and in a few convoluted tubules: the bulk of the pigment contained iron and little or no calcium (von Kossa). There was an appreciable but slight increase of the interstitial tissue discontinuously in the cortex associated with small foci of round cell infiltration. The mucosa of the renal pelvis was normal in appearance. The renal vasculature was normal.

'The renal lesion is an example of chronic glomerulonephritis. For the most part it seems to represent a late stage of Type 2 nephritis (Ellis), but it includes a few features which are more characteristic of the late stage of Type 1.'

\section{Group 4}

Case 17. A girl aged 2 years 11 months was admitted on January 19, 1935. One month before admission she developed a feverish cold and after an unspecified interval her body began to swell and her urinary output fell. On admission her breathing was distressed and she showed gross generalized oedema and ascites. Her blood urea was $24 \mathrm{mg}$. \%, her urine was loaded with albumin, and, on microscopic examination, contained many casts and a few red blood cells. Subsequent examinations showed no red blood cells, but casts and pus cells persisted. Respiratory embarrassment persisted in spite of abdominal paracentesis. Her urinary output continued low, her general condition deteriorated, and she died nine days after admission.

At necropsy there was generalized oedema and ascites; the only other abnormality noted was in the kidneys. The left kidney was grossly enlarged and pale, the right kidney was small and contained several infarcts.

Histologically 'the kidneys showed marked tubular nephritis of a subacute variety. The tubules showed marked fatty infiltration and degeneration over the entire kidney on the left and over the upper part on the right. The glomeruli and interstitial tissues were practically normal.'

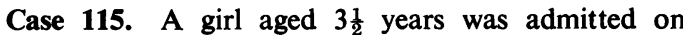
March 1, 1941. She had no history of recent infection. One week before admission oedema appeared, first in the face and later spreading to involve the entire body. She became drowsy, vomited at intervals, and complained of headache. On admission she was generally oedematous; her blood pressure was $104 / 84 \mathrm{~mm}$. $\mathrm{Hg}$ and blood urea level $30 \mathrm{mg}$. \%. The urine contained albumin, 13 parts Esbach, scanty red blood cells and many casts. She improved rapidly after admission and was discharged to rest at home after 17 days, the oedema having completely disappeared and the urine being practically free from albumin. She was re-admitted one month later with a recurrence of oedema, gross albuminuria, and scanty red blood cells in the urine. Her blood pressure was $116 / 90 \mathrm{~mm}$. $\mathrm{Hg}$ and blood urea level $39 \mathrm{mg}$. \%. The oedema increased steadily and her blood pressure rose to $120 / 100 \mathrm{~mm}$. $\mathrm{Hg}$. The blood cholesterol level was $710 \mathrm{mg} . \%$. After a terminal episode of fever and diarrhoea she died four months after the onset of the illness. There was no necropsy. 
Case 129. A boy aged 6 years was admitted on August 16, 1942. He had no history of recent infection. One week before admission his face began to swell and he vomited at intervals and complained of abdominal pain. On admission there was marked oedema of the face, back and legs. His blood pressure was 128/92 $\mathrm{mm}$. $\mathrm{Hg}$, and his blood urea level $52 \mathrm{mg}$. \%. The urine contained albumin ++ and a few red blood cells. For four months the oedema varied considerably and his blood pressure remained slightly raised. Albuminuria persisted, but the urine was usually free from red blood cells. He was discharged on December 28 to remain in bed at home. Oedema recurred intermittently till he was re-admitted on April 19, 1943, with gross generalized oedema. His blood pressure was then $115 / 80 \mathrm{~mm}$. $\mathrm{Hg}$ and his urine contained albumin +++ but no red blood cells. During the next month he improved considerably and when he was discharged on May 26 he was free from oedema and the urine showed a trace only of albumin. Thereafter he had no further symptoms and when he was seen over five years later he was well and the urine was normal.

Case 145. A girl aged 10 years was admitted on March 13, 1944. She had no history of recent infection. One month previously her face began to swell, she became drowsy, complained of headache and vomited intermittently. On admission she showed oedema of the face and legs. Her blood pressure was $120 / 90 \mathrm{~mm}$. Hg and blood urea level $23 \mathrm{mg}$. \%. The urine contained albumin ++ but no red blood cells. She was discharged after six weeks almost free from oedema but with albumin still present in the urine. One month later she was re-admitted with moderate oedema of the face and legs. Her blood pressure was then 136/100 $\mathrm{mm}$. $\mathrm{Hg}$ and the blood urea level $23 \mathrm{mg}$. \%. The blood cholesterol level varied between 684 and $984 \mathrm{mg}$. \%. She was discharged after three weeks, improved, but still with albuminuria. Repeated microscopic examination during both admissions had shown no red blood cells in the urine. Eight years later she was admitted to Aberdeen Maternity Hospital three months pregnant. She had slight oedema of the face and ankles; her blood pressure was $150 / 100 \mathrm{~mm}$. $\mathrm{Hg}$, blood urea level $20 \mathrm{mg}$. \%, and blood cholesterol level $190 \mathrm{mg}$. \%. The maximum specific gravity of the urine on a concentration test was 1,024. The urine contained albumin ++ and an Addis count on a 12-hour specimen showed 230,000 red blood cells and 317,000 casts. She was kept at rest throughout the greater part of the pregnancy and delivered of a live child by Caesarean section four weeks from term. Her blood pressure had tended to rise and albuminuria had increased towards the end of pregnancy, but, on her discharge 18 days after delivery, her blood pressure had fallen to $130 / 100 \mathrm{~mm}$. $\mathrm{Hg}$ and her albuminuria varied between 1 and $2 \cdot 5$ parts Esbach.

Case 161. A girl aged 1 year 4 months was admitted on January 8, 1945. Six weeks previously she developed a 'cold' and soon afterwards her face became swollen and her urine scanty and was found to contain albumin.
On admission she showed gross generalized oedema. The blood urea level was $28 \mathrm{mg}$. $\%$ and the blood cholesterol level $320 \mathrm{mg}$. \%. The urine contained albumin ++ and scanty red blood cells. No red blood cells were seen on further repeated urine examination; albuminuria and oedema steadily diminished and she was discharged after four weeks with normal urine. She has not been seen since, but in 1948 her mother reported that, after an apparent relapse lasting three weeks in April, 1945, she has remained well.

Case 176. A boy aged 6 years was admitted on January 21, 1946. Two weeks previously he developed a sore throat and a few days later his face began to swell. Oedema rapidly became generalized and he passed little urine. On admission he showed gross generalized oedema with ascites and bilateral pleural effusions. His blood pressure was $115 / 80 \mathrm{~mm}$. $\mathrm{Hg}$, blood urea level $27 \mathrm{mg} . \%$, blood cholesterol level $306 \mathrm{mg}$. \%, and plasma proteins $4.3 \mathrm{~g}$. \% with an albumin/globulin ratio of $0 \cdot 45 / 1$. The urine contained albumin ++++ and very scanty red blood cells. For three months his condition was virtually unchanged except that the blood urea rose to $110 \mathrm{mg}$. \%, then fell to $58 \mathrm{mg}$. \%. The urine continued to show albumin ++++ but scanty red blood cells were present only occasionally. Highprotein-low-salt diet, concentrated plasma transfusion, abdominal paracentesis, thyroid extract and 'neptal' all failed to produce any improvement in his general oedema. After three months he had a sudden spontaneous diuresis and in six days was completely free from oedema, which did not recur. Albuminuria to a lesser degree persisted until his transfer to Aberdeen City Hospital with chicken-pox on May 28. From there he was discharged home and was then seen as an out-patient at intervals until February, 1948. He remained very well and free from any symptoms, and the albuminuria rapidly diminished and ceased entirely by October, 1946. Thereafter his urine was normal on repeated examination. When last seen he was clinically well, his blood pressure was $110 / 80 \mathrm{~mm}$. $\mathrm{Hg}$, and his blood urea level $37 \mathrm{mg}$. \% .

Case 199. A girl aged 1 year 2 months was admitted on February 6, 1948. Two weeks before admission she developed a 'cold' and one week later her face and legs began to swell. On admission she showed oedema of the face and legs and signs of bronchitis. Her blood pressure was 110/90. The Wassermann reaction was negative. The urine contained albumin ++ and scanty red blood cells. The oedema rapidly became gross and generalized and then slowly disappeared: two weeks after admission the blood urea level was $32 \mathrm{mg}$. \% and the blood cholesterol level $736 \mathrm{mg}$. \%. She was discharged after 6 weeks free from oedema; the urine up to this time continued to show albumin ++ , but on only one occasion after the initial specimen were red blood cells present. She was seen again one year and almost four years after the onset of her symptoms, and on both occasions was clinically very well with normal urine.

Case A48. A girl aged 2 years was admitted on September 30, 1951. Three months before admission 
she had a sore throat from which she never really recovered. One month before admission her legs began to swell; the swelling varied from day to day and gradually spread to involve the whole body. On admission she showed moderately severe generalized oedema. Her blood pressure was $120 / 70 \mathrm{~mm}$. $\mathrm{Hg}$ and the blood urea level $24 \mathrm{mg}$. \%. The urine contained albumin +++ , scanty red blood cells and many casts. An Addis count on October 3 showed 228,000 red blood cells and 132,000 casts in a 12-hour specimen. Her weight slowly increased to $37 \mathrm{lb}$. one week after admission; during the next two weeks she had a moderate spontaneous diuresis and her weight fell to $30 \mathrm{lb}$., at which level she showed no obvious oedema. The urine continued to be loaded with albumin and an Addis count on October 17 showed 989,000 red blood cells and 556,000 casts in a 12-hour specimen. At this stage she developed measles and within one week of the onset albuminuria ceased and did not thereafter recur. During this time she was very well and her urine was repeatedly normal on routine examination. An Addis count on November 5 showed 64,000 red blood cells and 23,000 casts, and on November 14, 71,000 red blood cells and 5,900 casts. She was seen as an out-patient at intervals for over two years and remained very well, with normal blood pressure and urine. Four further Addis counts were well within normal limits.

\section{REFERENCES}

Clark, N. S. (1951). Archives of Disease in Childhood, 26, 351 Davson, J. and Platt, R. (1949). Quart. J. Med., 42 (New Series 18), 149

Ellis, A. (1942). Lancet, 1, 34 and 72

Enticknap, J. B. and Joiner, C. L. (1953). Brit. med. J., 1, 1016.

Fishberg, A. M. (1954). Hypertension and Nephritis, p. 654., 5th ed. Philadelphia.

Payne, W. W. and Illingworth, R. S. (1940). Quart. J. Med., 33 (N.S. 9), 37.

Snoke, A. W. (1937). Amer. J. Dis. Child., 53, 673. 